See discussions, stats, and author profiles for this publication at: https://www.researchgate.net/publication/338646174

\title{
Why Do the Young Generations Not Play Golf?
}

Article in Tourism Analysis · January 2020

DOI: $10.3727 / 108354220 \times 15758301241819$

CITATION

1

3 authors:

Miguel Portugal

Universidade Europeia

22 PUBLICATIONS 15 CITATIONS

SEE PROFILE

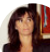

Antónia Correia

Universidade do Algarve

189 PUBLICATIONS 2,253 CITATIONS

SEE PROFILE
READS

616

Manuel Do Carmo

Academia Militar, Lisboa

12 PUBLICATIONS 48 CITATIONS

SEE PROFILE

Some of the authors of this publication are also working on these related projects:

Project Coleção Desafios da Globalização View project

Project Is the Sharing Economy Sustainable? Tourism Industry Perspective View project 


\title{
WHY DO THE YOUNG GENERATIONS NOT PLAY GOLF?
}

\author{
MIGUEL NUNO PORTUGAL,${ }^{*}$ MANUEL DO CARMO,${ }^{*} \dagger$ AND ANTÓNIA CORREIA* \\ *FTH, Universidade Europeia, Lisbon, Portugal \\ †CIMA-UE, Universidade de Évora, Évora, Portugal \\ †CEFAGE, Universidade do Algarve, Faro, Portugal
}

Golf is one of the most competitive sports for tourists in Portugal but not among the young generation. The young population often neglected this sport and categorized it as an elite sport for seniors. This situation may compromise the position Portugal has of the best golf destination in the world. To keep this position it is time to promote and attract young people starting with the residents. This research, exploratory in its essence, used a convenience sample to test why young people do not feel attracted to practice golf. The results suggest that there are very few teenagers willing to practice golf. The arguments are mostly this sport is not affordable, it is more tourist oriented, and is connoted as an eclectic social activity more than as a sport. These results, with evident implications on the attractiveness of golf, suggest that to overcome this situation the promotion should be oriented to attract young people.

\section{Key words: Golf; Young generations; Cluster; Perceptions, Portugal}

Introduction

In Portugal, tourism is currently boosting the economy and the country's development: the gross value added (GVA) is $8 \%$ of the gross domestic product (GDP) and accounts for $16.7 \%$ of the total exports of goods and services (Turismo de Portugal, 2017). The literature review reveals a great diversity of tourism typologies as well as their roles and the way they interact with the destinations. Within the new tourism modalities, characterized by several authors (Cohen, 1972; Pearce, 1985; Smith,
2012; Yiannakis \& Gibson, 1992), sports tourism, which includes golf, has been boosted with more demanding tourists (Bouchet, Lebrun, \& Auvergne, 2004) who are looking for a differentiated and personalized product.

Currently, it is estimated that there are about 52 million golf players around the world. The largest number occurs in the US (26 million), Japan (14 million), and Europe (6 million) (Ministério da Educação, 2018). Golf shouldn't be characterized only as a tourist product. It has increasingly gained a place in the context of the Meeting Industry, 
due to its position as an excellent resource for the creation of networking. Executives from different sectors gather to play golf, which promotes the emergence of new business opportunities (Dobrian, 2002; Nice, 2004). Nowadays, Portugal is one of the best destinations for those who desire to play golf. The most appealing factors for players are the diversified offer of golf courses, nature, and climate in Portugal throughout the year. There are currently 75 golf courses in Portugal, distributed through the Algarve (30), the Metropolitan Area of Lisbon (21), the North Region (13), the Central Region (5), and through the Autonomous regions of Madeira and Azores (6), making a total of 179 national clubs.

Portugal has been distinguished by the World Golf Awards as the best golf destination in the world for the third consecutive year. However, there are only a few international Portuguese golf players - only two on the European Tour. The practice of golf as a sport and its tournaments are one of the main motivations for attracting this type of tourism (golf tourism). Therefore, schools should play an important role in contributing to the growth and the popularity of this sport. Golf academies usually offer a variety of training packages, ranging from individual or group lessons to "first-swing" programs to start-up for practice or improvement of techniques, enabling the experience of playing in various areas of the field (chipping, pitching, or putting).

There is no upper limit for registration concerning age, though the minimum is 6 years old. The offer varies from academy to academy; however, all have the purpose of establishing an initial engagement of young people with the practice of the sport - the great majority provide the basic equipment for this. In 2016, the Portuguese golf federation endorsed several promotional actions, through which 14,000 children had contact with golf and 3,000 children participated in the Drive Challenge pilot circuit, in which 60 elementary schools participated (Federação Portuguesa de Golfe, http://portal.fpg.pt/).

Furthermore, over the year, 1,600 children enrolled in school sports. In Portugal 82 schools offer the possibility of joining a golf team. There are currently 4 school sports training centers in which 234 physical education teachers have had accredited training in golf. Moreover, 27 municipalities held golf workshops for elementary school teachers with the participation of 380 teachers. The large number of golf academies whose name originates in a foreign language is noteworthy. These are mainly in English, in order to attract the attention of young and future foreign clients, due to the fact that the majority of practitioners in Portugal are foreigners. Their marketing strategies are therefore positioned for their largest potential target client: foreign players (Federação Portuguesa de Golfe, http://portal.fpg.pt/).

The 2007 PENT, National Strategic Tourism Plan (Turismo de Portugal, 2008) considered golf one of the 10 strategic tourist products, because at the time there were more than 300,000 golf tourists per year, generating direct revenues in the order of 120 million euros, in addition to generating 3,000 direct jobs distributed across the 75 golf courses.

Currently in Portugal the vision for school sports promotes the practice of regular and quality physical and sports activities. Its mission is contributing to school success, to a healthy lifestyle, and to the development of social and moral values that are important for life in society such as solidarity, respect, responsibility, team spirit, tolerance, and dedication.

The most usual optional sports in school are futsal, basketball, handball, volleyball, and athletics. Golf as an option in school sports is very recent, which is the reason why the number of students enrolled in this sport is very low. The initiation of young people into the practice of golf through school/university sports is increasingly important for the recruitment of new players, taking into consideration the low-almost existent-number of young university student players in Portugal. Several factors emerge that may justify the small number of young Portuguese players, namely the feeling that it is a luxury sport, and is therefore not suited to all social classes. This exploratory study intends to increase the understanding of the main reasons for the lack of attractiveness of the practice of golf for students in higher education.

\section{Literature Review}

The origins of golf, regardless of the place or places where it was played for the first time and of all discussions around the subject, have always been associated with Scotland and the year 1522 when the Royal and Ancient Club of St. Andrews 
was founded (Ceron-Anaya, 2010; Pereira \& Correia, 2017; Reis \& Correia, 2013). The first reference to the game in Scotland goes back to 1457. In Portugal, it is estimated that the practice of golf, in an organized way, coincides with the founding of the Oporto Golf Club in 1880 (Federação Portuguesa de Golfe, http://portal.fpg.pt/).

Golf earned recognition as a sport back in the 16th century, although it was limited to the most favored social classes and became known in Europe and in Asia through colonialism by English and Scottish immigrants. Golf is most played nowadays in the US, but it was only in 1888 that the Scottish entrepreneur John Reid imported some golf clubs and balls from Scotland to the US, where he designed a rudimentary three-hole golf course near New York. Later he opened the American St. Andrews as the first American golf club (Hudson \& Hudson, 2010).

Due to the different variants that were at the origin of the game, the need for rule making was vital for the universalization of golf, and once again St. Andrews is closely connected to golf because it was responsible for establishing its first rules (Readman, 2003). Golf, in its official version, is played on 18-hole courses, with extensions of approximately $6 \mathrm{~km}$, involving several play areas such as the tee, fairway, rough, and green, which alternate with each other, including different obstacles like lakes, bunkers, or trees. These features make golf courses unique and help to differentiate them by combining their landscape with the architectural organization of the different elements of the game and with the natural and/or artificial obstacles (Perkins, 2010).

Golf is simultaneously a sporting practice and a form of leisure:

Golf is now global, it's played in almost every kind of environment. A desert course in Arizona is totally unlike new courses cut through the rainforest in Malaysia to satisfy the demand of Japanese hospitality tourism. Urban courses surrounded by golfing communities evoke different impressions from golf resorts isolated amongst wetlands. (Perkins, 2010, p. 314)

In countries where golf is a sport with financial relevance, governments usually support investment in the creation and in the maintenance of courses and academies, unlike countries where practice is reduced and where investment is the responsibility of the private sector for tourism purposes. In recent decades, the significant increase in the recognition of golf as a sporting modality and a source of income for Portugal (as well as in southern European countries such as France, Spain and Italy) is reflected in the large increase in enthusiasts who traveled for golf holidays and in the acquisition of holiday homes built within golf communities and golf resorts (Hudson \& Hudson, 2010).

The importance of golf should not only be recognized economically but also as a tourist attraction. It is a product that clearly fights seasonality and therefore becomes an excellent instrument for promoting a more equitable distribution of tourist demand throughout the year (Correia \& Tão, 2014). Golf tourists' satisfaction results from a combination of product performance, their expectations and desires. In the relational attitude theory, behavioral intentions are predictors of future behavior (Ajzen $\&$ Fishbein, 1980). Therefore, the need for constant improvement, by managers, in the quality of golf played at a certain destination will tend to increase players' satisfaction, thus increasing the potential number of visitors and consequently increasing additional revenue (Baker \& Crompton, 2000).

In a study carried out in 2014 (Completo \& Gustavo, 2014), the authors considered the balance between the offer of golf courses and professional players. The same authors also looked at the excessive dependence on developing models for companies offering complementary products (other tourism and real estate). Two possible scenarios for the development of golf in Portugal were presented by Completo and Gustavo as a possible way to keep the existing offer on golf courses and guarantee that Portugal will be a competitive and sustainable golf destination, both at an economic and social level:

1. Portugal was internationally recognized as a golf destination. In this scenario the golf in Portugal must necessarily be reformulated, as supply will be excessive considering the current golf demand in Portugal. The demand comes mostly from foreign markets and is highly seasonal. Golf, as a tourism product, plays a relevant role concerning the sustainability of Portugal as a tourism destination and as a complementary product to the sun-and-beach tourism. Furthermore, the market dimension must be taken into 
consideration - currently insufficient to guarantee economic and financial sustainability of golf courses.

2. Golf as a leisure activity/sport for the Portuguese. "In addition to the tourism dimension identified in the scenario above, golf tends to be assumed as a leisure activity in the Portuguese cultural and sport universe. This demands the definition of a strategic plan of development for golf, regarding both demand and supply" (Completo \& Gustavo, 2014, p. 151).

\section{Methodology}

In relation to the research methodologies used in this study, a structured questionnaire was developed in six sections (sociodemographic characterization, situational factors regarding the practice of golf, factors that could make the practice of golf more fun/appealing, factors considered fundamental for the practice of golf, factors discouraging the practice of golf and, in section 6, questions on sports that the respondents were currently playing besides golf), applied face-to-face to 1,336 students enrolled in Bachelor and Master degree programs, of different years, of a private university in Lisbon. Nonprobabilistic sampling was used and a response rate of $100 \%$ was obtained.

For the analysis of the results, first the situational factors were aggregated regarding the practice of golf in a dichotomous variable, $0=$ never played and 1 = already played, which was used as an endogenous variable in binary logistic regression models. Descriptive statistics were used for the sociodemographic characterization of the sample and a two-step cluster analysis (TSCA) was applied, in each section, to obtain indicators of the importance of possible predictors. Finally, a binary logistic regression was used to evaluate the reasons for the lack of attractiveness of the practice of golf for students in higher education.

The use of cluster analysis in two steps is justified, as it allows the relevance of the predictor ("construct" or item) to be obtained in a subsequent regression analysis, with no requirement to be defined as a dependent variable.

Traditional clustering methods are efficient and rigorous when applied to small datasets. When the dataset is more extended, as in this case, to apply the traditional methods it is necessary to reduce the size of the database previously, and then the grouping is carried out in two steps as Balanced Iterative Reducing and Clustering using Hierarchies (BIRCH) (Zhang, Ramakrishnan, \& Livny, 1996). The two-step cluster method uses this procedure, allowing a response to large datasets (particularly well suited to the structural approach of multiple indicators) and the use of continuous, categorical variables or the two variable types simultaneously. The method consisted of the following steps:

- First step: formation of a series of preclusters, aiming to reduce the matrix size of distances between all possible pairs of cases. At this stage, the data are traversed one by one, and the algorithm decides whether a given individual should migrate to a preformed precluster or start a new precluster. At the end of this procedure, all individuals belonging to the same precluster are treated as a single entity. Thus, the distance matrix is smaller because its size depends on the number of preclusters.

- Second step: grouping the preclusters. In the second step, the hierarchical grouping was formed (of the preclusters formed in the previous stage) according to the number of clusters desired.

In this method, the log-likelihood function is used in the calculation of the distance measures, and because it works only with categorical variables, the distance between two clusters is expressed by the decrease of the log-likelihood function. In this case, the algorithm provides better results when the multinomial distribution is verified. The main advantages of this method are the use of noncontinuous variables and easy interpretation, making information available about the importance of each variable in the formation of each cluster and a measure of the statistical significance, called average silhouette (chi-square for noncontinuous variables), allowing the confirmation of the defined profiles (Tkaczynski, 2017). The main advantage here is the use of categorical variables (this is the case of this research), grouping in two steps, thus increasing the efficiency of the method, and the algorithm itself finds an optimal number of clusters. The average silhouette, proposed by Kaufman and Rousseeuw (1990), is a measure of the clustering solution's overall goodness-of-fit and 
is used to estimate the optimal number of clusters. For the observation $(i)$, let us consider $a(i)$ the average of the distances of this point to the other points of this cluster and $b(i)$ the average of the distances to the points of the nearest cluster. In this way, the silhouette statistic is defined by:

$$
s(\mathrm{i})=\frac{b(\mathrm{i})-a(\mathrm{i})}{\max [a(\mathrm{i}), b(\mathrm{i})]}
$$

One point is well classified if $s(i)$ is large. The authors proposed the choice of the optimal value of some clusters $k$, as the value that maximizes the average of the whole dataset, with $s(i)$ not being defined when $k=1$. It is mostly based on the average distances between the objects and can vary between -1 and +1 ; specifically, a silhouette measure below 0.20 indicates a poor solution quality, a measure between 0.20 and 0.50 a fair solution, whereas values over 0.50 indicate an acceptable solution (Mooi \& Sarstedt, 2011).

For the automatic determination of the number of clusters, SPSS developed the two-step procedure, compatible with hierarchical cluster analysis, which is the first step used in the Bayes information criterion (BIC) or the Akaike information criterion (AIC). In the second step, the initial estimate is improved when the maximum distance between the two closest clusters is found at each step of the hierarchical cluster. In this case the BIC was úsed in the first step.

In relation to the binary logistic regression, this is a particular case of categorical regression since the endogenous variable under study is nominal dichotomous $(0=$ never played and $1=$ already played). For each of the models considered logits, odds, and odds ratios will be obtained and adjustments will be obtained by the maximum likelihood method. The confidence intervals will be calculated for the all coefficients of the model and the significance and quality of the model will be measured by the chi-square and Wald tests. The chi-square is the test of the adjustment and the Wald of the significance of the coefficients of the model, as well as of the pseudo- $R^{2}$, where the selection of the predictors ("best" adjusted model) is done by the forward method based on the Wald test (stepwise selection method. In this case the entry of an exogenous variable into the model is made according to the significance of the "score," and the removal of one variable from the model is made according to the significance of the Wald test (Maroco, 2014).

According to the methodology presented, three models of binary logistic regression will be considered, always having as endogenous variables the situational factors regarding the practice of golf $(0=$ never played and 1 = already played). The gender $(\mathrm{G})$, age range (AR), cycle of studies frequented (CS), year of enrolment (YE), the timetable shift frequented $(\mathrm{T})$, and the number of the sports currently played (S6) $(0,1,2$, or more) are considered variables for all models. Additionally, in the first model, the variables corresponding to the response hypotheses of section 3 of the questionnaire will be considered (treated as dummy). Also, in the second model, the variables corresponding to the response hypotheses of section 4 of the questionnaire will be considered (treated as dummy), and in the third model, the variables corresponding to the hypotheses under evaluation in section 5 of the questionnaire also will be treated as dummy (Aljandali, 2017).

\section{Results}

The research methodology was quantitative, based on a face-to-face questionnaire applied to a sample of 1,336 students, and 794 (59.4\%) were female. Of the total, 43 (3.2\%) were under 19 years old, 947 were between 19 and 23 years old $(70.9 \%)$, $233(17.4 \%)$ were between 24 and 30 years old, 110 $(8.2 \%)$ were between 31 and 54 years old, and 3 $(0.2 \%)$ were over 54 years old. From the percentages of the age groups it is possible to understand that the majority were enrolled in a bachelor's degree program $[1,227(91.8 \%)]$ and the remainder in a master's degree program [109 (8.2\%)], with 489 (36.6\%) attending the first year, 407 (30.5\%) the second year, $420(31.4 \%)$ the third year, and $20(1.5 \%)$ the fourth year. The majority $[1,044$ (78.1\%)] attended regular daytime teaching and the remainder (21.9\%) had after-work classes.

Applying two-step cluster analysis to section 3, factors that would make the practice of golf more fun/appealing, three optimal clusters were obtained with average silhouette equal to 1 (good), indicating the existence of a good separation distance between the clusters, considering that all items within them are statistically significant $(p<0.05)$.

\section{1}




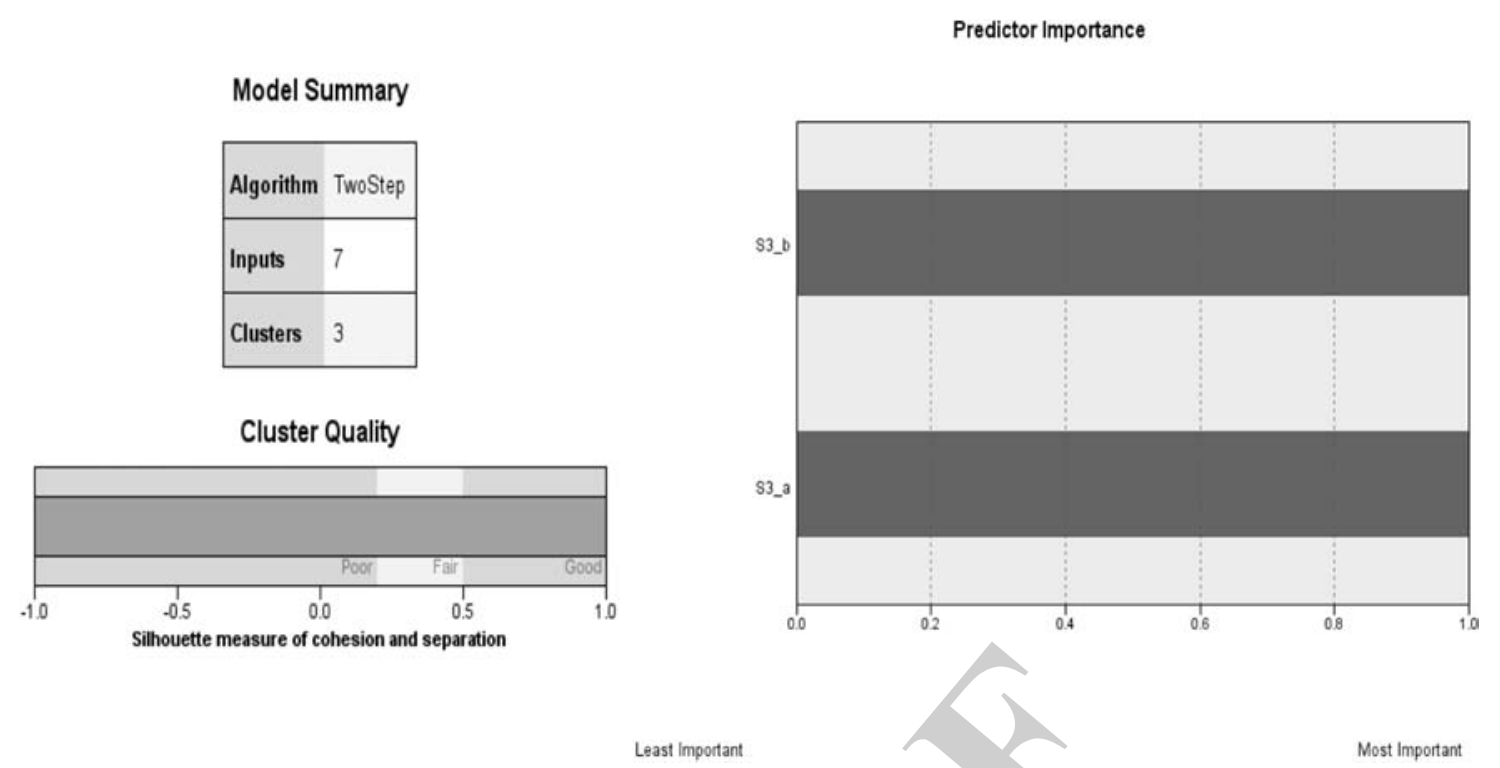

Figure 1. Optimal number of the cluster denominated by family and friends.

By the criterion of the importance of the predictor, the factors considered most important are: "To have close friends who play golf" and "To have family members who play golf” (Fig. 1).

When the binary logistic regression was applied under the conditions described above, a model was obtained (in four steps) $m$ which indicates that the variables gender $(\mathrm{G})\left[\beta_{\mathrm{G}}=0.679 ; \chi_{\text {Wald }}^{2}(1)=24.72\right.$; $p=0.001$ and odds ratio $=1.972]$, cycle of studies $(\mathrm{CS})\left[\beta_{\mathrm{CS}}=-0.751 ; \chi_{\text {Wald }}^{2}(1)=11.78 ; p=0.001\right.$ and odds ratio $=0.472]$, to have close friends who play golf $\left[\mathrm{S} 3 \_b\right)\left(\beta \mathrm{S} 3 \_\mathrm{b}=0.450 ; \chi_{\text {Wald }}^{2}(1)=9.36\right.$; $p=0.002$ and odds ratio $=1.569]$, and don't know anyone who plays golf $(\mathrm{S} 3$ _c $)[\beta \mathrm{S} 3$ c $=0.981$; $\chi_{\text {Wald }}^{2}(1)=6.139 ; p=0.013$ and odds ratio $\left.=2.668\right]$ present a statistically significant effect on logit of the probability of already having played golf according to the adjusted logit model [G2(4) $=47.58$ and $p<$ $0.001 ; \chi_{\text {Wald }}^{2}(3)=2.212 ; p=0.530 ; R_{\mathrm{CS}}^{2}=0.035$; $\left.R^{2}{ }_{\mathrm{N}}=0.054\right]$. Table 1 provides the coefficients of the model and their significance.

Under these conditions, the probability of having played golf $(\mathrm{Y}=1)$ increases exponentially with gender (especially when it reports to the masculine type) and with having friends or acquaintances who already play golf. On the opposite, the result

Table 1

The Coefficients Logit of the Logistic Regression Model of the Variable Situational Factors in Relation to the Practice of Golf as a Function of the Gender, Cycle of Studies, To Have Close Friends Who Play Golf, and Don’t Know Anyone Who Plays Golf

\begin{tabular}{lrrrrrrrrr}
\hline & & & & & & & & \multicolumn{2}{c}{$95 \%$ CI for $\operatorname{Exp}(\beta)$} \\
\cline { 5 - 9 } Step 4 & \multicolumn{1}{c}{$\beta$} & \multicolumn{1}{c}{ SE } & Wald & $d f$ & Sig. & $\operatorname{Exp}(\beta)$ & Lower & Upper \\
\hline G(1) & 0.679 & 0.137 & 24.721 & 1 & 0.000 & 1.972 & 1.509 & 2.577 \\
CS(1) & -0.751 & 0.219 & 11.776 & 1 & 0.001 & 0.472 & 0.307 & 0.725 \\
S3_b(1) & 0.450 & 0.147 & 9.362 & 1 & 0.002 & 1.569 & 1.176 & 2.093 \\
S3_c(1) & 0.981 & 0.396 & 6.139 & 1 & 0.013 & 2.668 & 1.228 & 5.800 \\
Constant & -2.017 & 0.454 & 19.702 & 1 & 0.000 & 0.133 & & \\
\hline
\end{tabular}


decreases according to the study cycle were students here assigned [possibly due to the age, status, labor condition, or even the availability of the time (lower when if attending a bachelor's degree program because of workload)].

In relation to section 4 , the factors considered to be fundamental to the practice of golf, four optimal clusters were obtained with an average silhouette equal to 0.4 (reasonable), indicating the existence of a reasonable separation distance between the clusters, considering that all the items within them are statistically significant $(p<0.05)$. By the criterion of the importance of the predictor, the four most important factors are "Reduce stress," "Contact with nature," "Good way to spend time with friends and/or family," and "Good for business" (Fig. 2).

When the binary logistic regression was applied, the model obtained (in four steps) indicates that the variables gender $(\mathrm{G})\left[\beta_{\mathrm{G}}=0.642 ; \chi_{\text {Wald }}^{2}(1)=22.05\right.$; $p=0.001$ and odds ratio $=1.900]$, cycle of studies (CS) $\left[\beta_{\mathrm{CS}}=-0.733 ; \chi_{\text {Wald }}^{2}(1)=11.20 ; p=0.001\right.$ and odds ratio $=0.480]$, golf carts $\left(S 4 \_j\right)[\beta S 4 j \mathrm{j}=0.402$; $\chi_{\text {Wald }}^{2}(1)=4.11 ; p=0.043$ and odds ratio $\left.=1.495\right]$, and earning (S4_k) $\left[\beta S 4 \_\mathrm{k}=0.441 ; \chi_{\text {Wald }}^{2}(1)=\right.$ 4.627; $p=0.031$ and odds ratio $=1.554$ ] present a statistically significant effect on logit of the probability of already having played golf according to the adjusted logit model $[\mathrm{G} 2(4)=43.75$ and $p<$ $0.001 ; \chi_{\text {Wald }}^{2}(5)=7.049 ; p=0.217 ; R_{\text {CS }}^{2}=0.032$; $\left.R_{\mathrm{N}}^{2}=0.050\right]$. Table 2 presents the coefficients of the model and their significance.

In this way, the probability of having played golf $(\mathrm{Y}=1)$ increases exponentially with gender (again, and in particular, when it comes to the male gender), because there are golf trolleys transporting the material necessary to play golf and because of the fact that it involves learning (solving new situations in each new move that will be a challenge), decreasing, as in section 4, with the cycle of studies enrolled in.

In relation to section 5, and fundamental, reasons for the lack of attractiveness of playing golf for students of higher education, two optimal clusters were obtained with average silhouette equal to 0.4 (reasonable), also indicating the existence of a distance of reasonable separation between clusters, considering that all items within them are statistically significant $(p<0.05)$. By the criterion of the importance of the predictor, the four most important factors are "Price of the game/golf courses," "Equipment price," "All," and "Absence of friends playing golf" (Fig. 3).

With the binary logistic regression, a model was obtained (in 5 steps) which indicates that the variables gender $(\mathrm{G})\left[\beta_{\mathrm{G}}=0.625 ; \chi_{\text {Wald }}^{2}(1)=20.59\right.$;

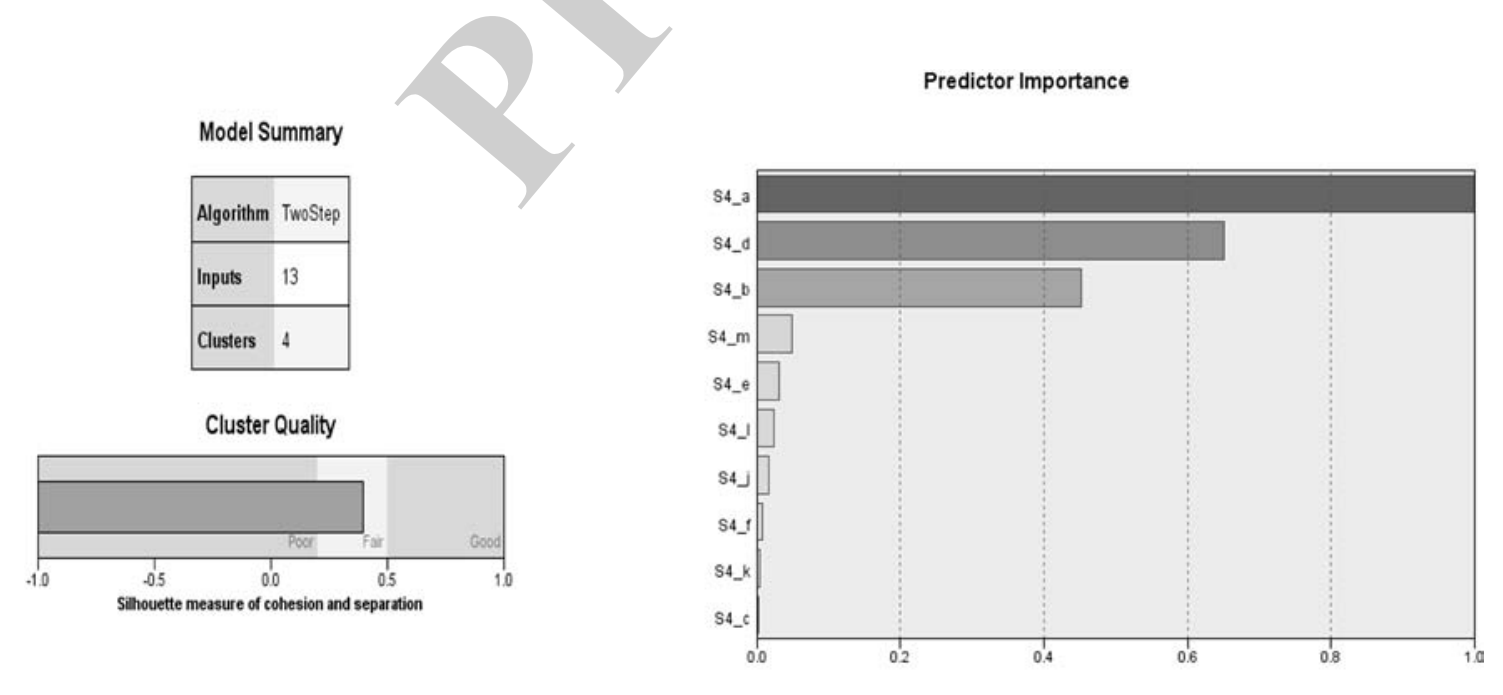

Figure 2. Optimal number of the cluster denominated by health and nature. 
Table 2

The Coefficients Logit of the Logistic Regression Model of the Variable Situational Factors in Relation to the Practice of Golf as a Function of the Gender, Cycle of Studies, Golf Carts, and Learning

\begin{tabular}{|c|c|c|c|c|c|c|c|c|}
\hline \multirow[b]{2}{*}{ Step 4} & \multirow[b]{2}{*}{$\beta$} & \multirow[b]{2}{*}{$S E$} & \multirow[b]{2}{*}{ Wald } & \multirow[b]{2}{*}{$d f$} & \multirow[b]{2}{*}{ Sig. } & \multirow[b]{2}{*}{$\operatorname{Exp}(\beta)$} & \multicolumn{2}{|c|}{$95 \% \mathrm{CI}$ for $\operatorname{Exp}(\beta)$} \\
\hline & & & & & & & Lower & Upper \\
\hline $\mathrm{G}(1)$ & 0.642 & 0.137 & 22.045 & 1 & 0.000 & 1.900 & 1.454 & 2.484 \\
\hline CS(1) & -0.733 & 0.219 & 11.202 & 1 & 0.001 & 0.480 & 0.313 & 0.738 \\
\hline $\mathrm{S} 4 \mathrm{j}(1)$ & 0.402 & 0.198 & 4.111 & 1 & 0.043 & 1.495 & 1.014 & 2.204 \\
\hline $\mathrm{S} 4 \overrightarrow{\mathrm{k}}(1)$ & 0.441 & 0.205 & 4.627 & 1 & 0.031 & 1.554 & 1.040 & 2.323 \\
\hline Constant & -1.649 & 0.327 & 25.375 & 1 & 0.000 & 0.192 & & \\
\hline
\end{tabular}

$p=0.001$ and odds ratio $=1.868]$, cycle of studies (CS) $\left[\beta_{\mathrm{CS}}=-0.818 ; \chi_{\text {Wald }}^{2}(1)=13.61 ; p=0.001\right.$ and odds ratio $=0.441$ ], price of the game/golf courses (S5_a) [BS5_a $=0.682 ; \chi_{\text {Wald }}^{2}(1)=23.494 ; p=0.001$ and odds ratio $=1.977]$, absence of communication/information $(S 5 j)\left[\beta S 5 j \mathrm{j}=0.519 ; \chi_{\text {Wald }}^{2}(1)=\right.$ 4.056; $p=0.044$ and odds ratio $=1.681]$, and all (S5_n) $\left[\beta S 5 \_\mathrm{n}=1.002 ; \chi_{\text {Wald }}^{2}(1)=8.680 ; p=0.003\right.$ and odds ratio $=2.725]$ present a statistically significant effect on logit of the probability of already having played golf according to the adjusted logit model $\left[\mathrm{G} 2(5)=66.98\right.$ and $p<0.001 ; \chi_{\text {Wald }}^{2}(5)=$ $\left.1.167 ; p=0.948 ; R_{\mathrm{CS}}^{2}=0.049 ; R_{\mathrm{N}}^{2}=0.076\right]$. Table 3 provides the coefficients of the model and their significance.

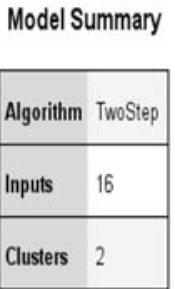

\section{Cluster Quality}

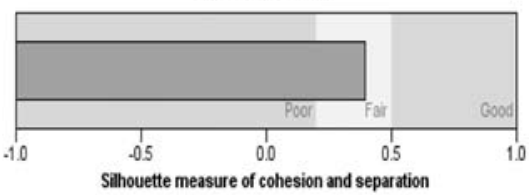

In this way, it was verified that the probability of playing golf $(\mathrm{Y}=1)$ increases exponentially with gender (variable present in all models), price of the game/golf courses, absence of communication/ information, and all factors considered in the question, decreasing, as in the other situations considered, with the cycle of studies enrolled in.

\section{Conclusion}

These results, although exploratory, confirm previous research. Golf is a highly masculine sport (Reis \& Correia, 2013), eminently social (Correia \& Kozak, 2012), perceived as nonaffordable in economic terms (Correia \& Kozak, 2012), and needs

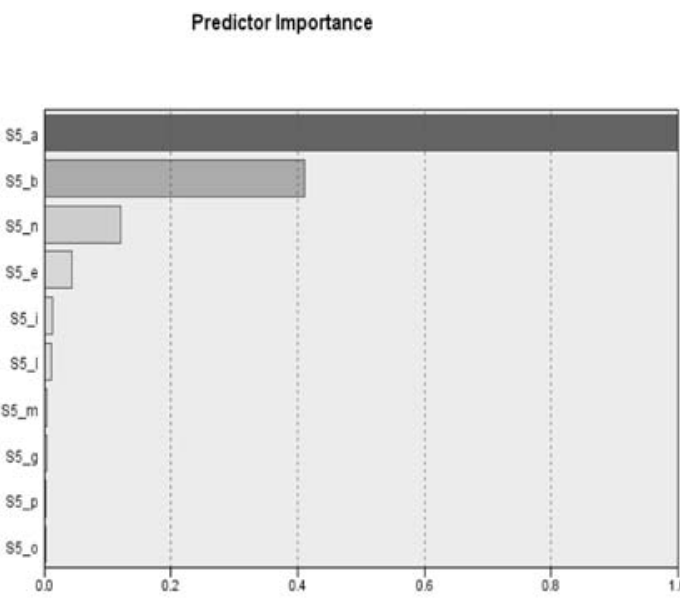

Least Important

Figure 3. Optimal number of the cluster denominated by price of the game/golf courses. 
Table 3

The Coefficients Logit of the Logistic Regression Model of the Variable Situational Factors in Relation to the Practice of Golf as a Function of the Gender, Cycle of Studies, Price of the Game/ Golf Courses, Absence of Communication/Information, and All

\begin{tabular}{lrrrrrrrr}
\hline & & & & & & & & \multicolumn{2}{c}{$95 \%$ CI for $\operatorname{Exp}(\beta)$} \\
\cline { 5 - 9 } Step 5 & \multicolumn{1}{c}{$\beta$} & \multicolumn{1}{c}{$S E$} & Wald & $d f$ & Sig. & $\operatorname{Exp}(\beta)$ & Lower & Upper \\
\hline G(1) & 0.625 & 0.138 & 20.586 & 1 & 0.000 & 1.868 & 1.426 & 2.446 \\
CS(1) & -0.818 & 0.222 & 13.609 & 1 & 0.000 & .441 & 0.286 & 0.682 \\
S5_a(1) & 0.682 & 0.141 & 23.494 & 1 & 0.000 & 1.977 & 1.501 & 2.604 \\
S5_j(1) & 0.519 & 0.258 & 4.056 & 1 & 0.044 & 1.681 & 1.014 & 2.785 \\
S5_n(1) & 1.002 & 0.340 & 8.680 & 1 & 0.003 & 2.725 & 1.399 & 5.308 \\
Constant & -2.547 & 0.461 & 30.463 & 1 & 0.000 & 0.078 & & \\
\hline
\end{tabular}

more and better promotion (Pereira, Correia, \& Schultz, 2014). If these characteristics were changed the sport would be more attractive to young people. Although the sample has a considerable dimension, this study's main limitation is due to the fact that it is composed only of higher education students from a single private university, which may have implications in the conclusions. In order to overcome this limitation, it is intend to carry out an inference study, considering young people from different social settings and with different age groups.

Despite the limitations, the results suggest that golf is perceived as a sport for older people; the attractiveness of the golf courses is compromised also in a sample of young people that could afford to play golf. This suggests that the lack of competitiveness of golf as a sport is far apart from the social status golf has. Other factors are affecting the practice of this sport - the duration of the course, the lack of mediatize, and the high market share golf has with the older people are some of the factors that are compromising the promotion of golf with young people. This is a problem that should be overcome shortly to make golf more competitive and to ensure the market share golf has nowadays.

\section{References}

Ajzen, I., \& Fishbein, M. (1980). Understanding attitudes and predicting social behaviour. Englewood Cliffs, NJ: Prentice-Hill.

Aljandali, A. (2017). Multivariate methods and forecasting with IBM ${ }^{\circledR}$ SPSS ${ }^{\circledR}$ statistics. Cham, Switzerland: Springer.

Baker, D., \& Crompton, J. (2000). Quality, satisfaction and behavioral intentions. Annals of Tourism Research, 27(3), 785-804.
Bouchet, P., Lebrun, A. M., \& Auvergne, S. (2004). Sport tourism consumer experiences: A comprehensive model. Journal of Sport \& Tourism, 9(2), 127-140.

Ceron-Anaya, H. (2010). An approach to the history of golf: Business, symbolic capital, and technologies of the self. Journal of Sport and Social Issues, 34, 339-358.

Cohen, E. (1972). Toward a sociology of international tourism. Social Research, 39(1), 164-182.

Completo, F., \& Gustavo, N. (2014). Golf tourism destination management: Looking for a sustainable demand: The case of Portugal. Journal of Management and Sustainability, 4(1), 142.

Correia, A., \& Kozak, M. (2012). Exploring prestige and status on domestic destinations: The case of Algarve. Annals of Tourism Research, 39(4), 1951-1967.

Correia, A., \& Tão, M. (2014). Fatores de atratividade e sustentabilidade do golfe: A experiência do Algarve. In C. Costa, F. Brandão, R. Costa, \& Z. Breda (Eds.), Produtos e Competitividade do Turismo na Lusofonia (pp. 271-284). Lisboa, Portugal: Escolar Editora.

Dobrian, J. (2002). Golf grows up, American Heritage, 53(5), 4-15

Hudson, S., \& Hudson, L. (2010). Golf tourism. Oxford, UK: Goodfellow Publishers Limited.

Kaufman, L., \& Rousseeuw, P. J. (1990). Finding groups in data: An introduction to cluster analysis. New York, NY: John Wiley \& Sons.

Maroco, J. (2014). Análise de Estatística com o SPSS Statistics, $6^{a}$ Edição, ReportNumber.

Ministério Educação. (2018). Portal do Desporto Escolar do Ministério da Educação. Retrieved from http://desportoescolar.dge.mec.pt.

Mooi, E., \& Sarstedt, M. (2011). A concise guide to market research the process, data, and methods using IBM SPSS statistics. Berlin, Germany: Springer.

Nice, B. (2004). Golf in meetings, incentives, conventions, exhibitions (mice) tourism: Perceptions of meeting planners (master's thesis). Retrieved from http://ufdcimages. uflib.ufl.edu/UF/E0/00/69/82/00001/nice_b.pdf

Pearce, P. L. (1985). A systematic comparison of travelrelated roles. Human Relations, 38(11), 1001-1011. 
Pereira, R., \& Correia, A. (2017). Turismo de Golfe, In F. Silva \& J. Umbelino (Eds.), Planeamento e Desenvolvimento Turístico (pp. 303-311). Lisboa, Portugal: Edições Lidel.

Pereira, R., Correia, A., \& Schultz, R. (2014). Destination brand personality: Searching for personality traits on golf- related websites. Anatolia: An International Journal of Tourism and Hospitality Research, 25(3), 387-402.

Perkins, C. (2010). The performance of golf: Landscape, place, and practice in North West England. Journal of Sport and Social Issues, 34, 312-338.

Readman, M. (2003). Golf tourism. In Hudson, S. (Ed.). Sport and adventure tourism (pp. 165-202). London, UK: Haworth Hospitality Press.

Reis, H., \& Correia, A. (2013). Gender asymmetries in golf participation. Journal of Hospitality Marketing and Management, 22(1), 67-91.

Smith, V. L. (Ed.). (2012). Hosts and guests: The anthropology of tourism. Philadelphia, PA: University of Pennsylvania Press.
Tkaczynski, A. (2017). Segmentation using two-step cluster analysis. In T. Dietrich, S. Rundle-Thiele \& K. Kubacki (Eds.), Segmentation in social marketing, process, methods and application (pp. 109-125). Singapore: Springer.

Turismo de Portugal. (2008). PENT-Plano Estratégico Nacional do Turismo: para o desenvolvimento do turismo em Portugal. Retrieved from https://ravelbi.turismode portugal.pt/pt-pt/Documents/Estrat\%C3\%A9gia/PENT_ 2007.pdf

Turismo de Portugal. (2017). Apresentação da Estratégia Turismo 2027: 15 de março na BTL. Turismo de Portugal. Retrieved from: http://estrategia.turismodeportugal.pt

Yiannakis, A., \& Gibson, H. (1992). Roles tourists play. Annals of Tourism Research, 19(2), 287-303.

Zhang, T., Ramakrishnan, R., \& Livny, M. (1996). BIRCH: An efficient data clustering method for very large databases. Proceedings of the ACM SIGMOD International Conference on Management of Data-SIGMOD'96. Montreal, Canada (pp. 103-114). Retrieved from https://www2. cs.sfu.ca/CourseCentral/459/han/papers/zhang96.pdf 